\title{
The Effects of Physiological Biomechanical Loading on Intradiscal Pressure and Annulus Stress in Lumbar Spine: A Finite Element Analysis
}

\author{
Siti Nurfaezah Zahari, ${ }^{1}$ Mohd Juzaila Abd Latif, ${ }^{1,2}$ Nor Raihanah Abdull Rahim, ${ }^{3}$ \\ Mohammed Rafiq Abdul Kadir, ${ }^{3}$ and Tunku Kamarul ${ }^{4}$ \\ ${ }^{1}$ Faculty of Mechanical Engineering, Universiti Teknikal Malaysia Melaka, Hang Tuah Jaya, 76100 Durian Tunggal, \\ Melaka, Malaysia \\ ${ }^{2}$ Center for Robotics and Industrial Automation (CeRIA), Universiti Teknikal Malaysia Melaka, Hang Tuah Jaya, \\ 76100 Durian Tunggal, Melaka, Malaysia \\ ${ }^{3}$ Medical Devices and Technology Group, Faculty of Biosciences and Medical Engineering, Universiti Teknologi Malaysia, \\ 81310 Skudai, Johor, Malaysia \\ ${ }^{4}$ Tissue Engineering Group (TEG), National Orthopaedic Centre of Excellence in Research and Learning (NOCERAL), Department of \\ Orthopaedic Surgery, Faculty of Medicine, University of Malaya, Lembah Pantai, 50603 Kuala Lumpur, Malaysia
}

Correspondence should be addressed to Mohd Juzaila Abd Latif; juzaila@utem.edu.my

Received 5 May 2017; Revised 10 July 2017; Accepted 24 July 2017; Published 27 August 2017

Academic Editor: Lizhen Wang

Copyright (c) 2017 Siti Nurfaezah Zahari et al. This is an open access article distributed under the Creative Commons Attribution License, which permits unrestricted use, distribution, and reproduction in any medium, provided the original work is properly cited.

\begin{abstract}
The present study was conducted to examine the effects of body weight on intradiscal pressure (IDP) and annulus stress of intervertebral discs at lumbar spine. Three-dimensional finite element model of osseoligamentous lumbar spine was developed subjected to follower load of $500 \mathrm{~N}, 800 \mathrm{~N}$, and $1200 \mathrm{~N}$ which represent the loads for individuals who are normal and overweight with the pure moments at $7.5 \mathrm{Nm}$ in flexion and extension motions. It was observed that the maximum IDP was $1.26 \mathrm{MPa}$ at L1-L2 vertebral segment. However, the highest increment of IDP was found at L4-L5 segment where the IDP was increased to $30 \%$ in flexion and it was more severe at extension motion reaching to $80 \%$. Furthermore, the maximum annulus stress also occurred at the L1-L2 segment with $3.9 \mathrm{MPa}$ in extension motion. However, the highest increment was also found at L4-L5 where the annulus stress increased to $17 \%$ in extension motion. Based on these results, the increase of physiological loading could be an important factor to the increment of intradiscal pressure and annulus fibrosis stress at all intervertebral discs at the lumbar spine which may lead to early intervertebral disc damage.
\end{abstract}

\section{Introduction}

Obesity has been recognised as a factor that could lead to chronic low back pain (LBP). This problem is expected to further escalate in the near future with the current increasing numbers of overweight and obese population $[1,2]$. It was demonstrated that the increase of body weight will increase the stress at the lumbar spine which leads to potential factor of intervertebral disc (IVD) degeneration [3-6]. Furthermore, excessive loading applied on the lumbar spine tends to fracture the vertebral body endplate before damaging the IVD [7].

In computational studies, follower load applied to the lumbar spine could increase intradiscal pressure (IDP), intersegmental rotation and facet joint force $[8,9]$. The compressive load on the spine reduces the disc height due to the decrease of the volume of mass gelatinous in nucleus pulposus. As the fluid is being squeeze out from the disc, the tissue will reorganize which caused the viscoelastic annulus collagen fibers to creep $[10,11]$. Consequently, this increases the hydrostatic 


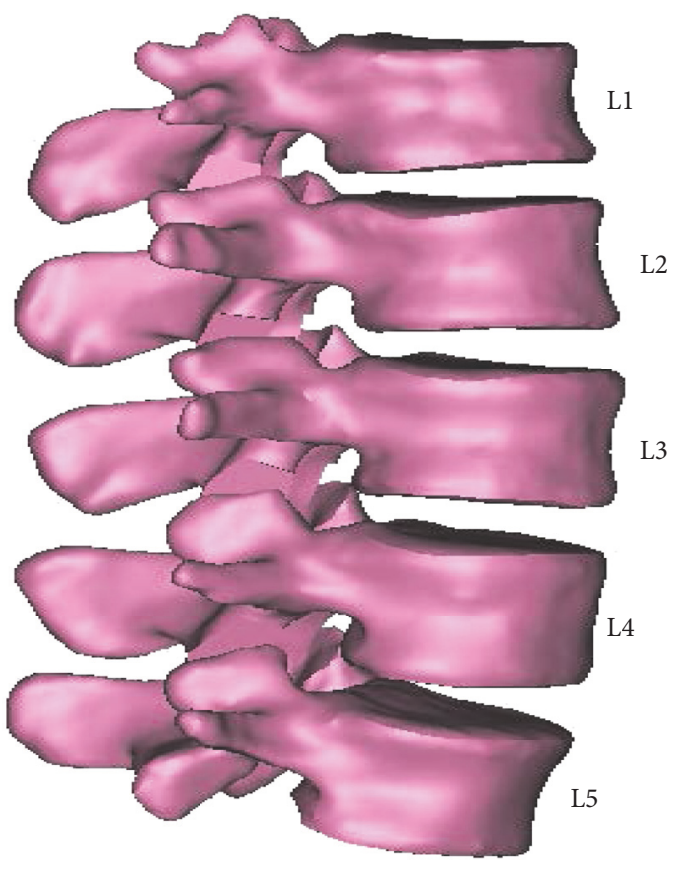

(a)

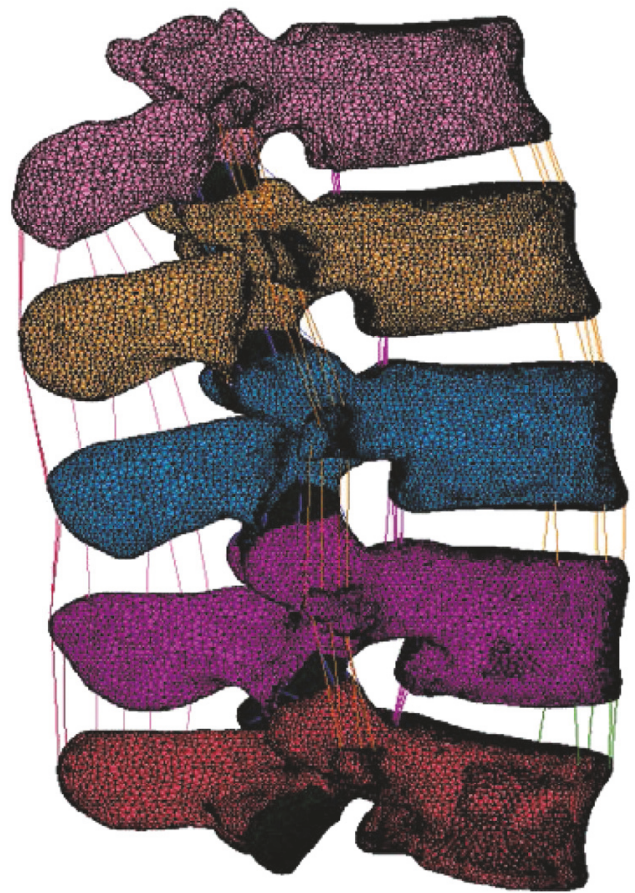

(b)

Figure 1: L1-L5 lumbar spine. (a) Three-dimensional model and (b) finite element model.

pressure and the outer annulus starts to bulge. Although these phenomenons have been described in many computational and clinical studies, the fundamental understanding that underpins the biomechanics leading to disc damage has yet to be explored. Furthermore, the relationship between the increase in body weight to the stresses occurs at various vertebral segments of the lumbar spine when the body in different posture needs to be elucidated.

In the present study, the effects of physiological loading on the lumbar spine were studied at all vertebral segments to examine the IVD during flexion and extension motions using finite element method. The IDP at nucleus pulposus and the von Mises stress (VMS) at annulus fibrosis of the IVD were investigated.

\section{Materials and Methods}

2.1. Finite Element Modeling. The geometrical data of lumbar vertebrae were obtained from computed tomography (CT) scan of a healthy 21-year-old male with $1.73 \mathrm{~m}$ height and $70 \mathrm{~kg}$ weight. The CT scan images of $3 \mathrm{~mm}$ slice thickness in two-dimensional (2D) Standard Tessellation Language (STL) format were segmented to develop a threedimensional (3D) model of human lumbar spine using Mimics 14.0 (Materialise, Leuven, Belgium) and Magics (Materialise, Leuven, Belgium) softwares as shown in Figure 1(a). Marc Mentat 2011 (MSC, Software, Santa Ana, $\mathrm{CA}$ ) finite element (FE) software was then used to generate the FE model using linear first-order tetrahedral elements as shown in Figure 1(b).
TABle 1: Geometrical parameters of the lumbar spine ligaments $[15,18]$.

\begin{tabular}{lc}
\hline Ligaments & Cross-sectional area $\left(\mathrm{mm}^{2}\right)$ \\
\hline Posterior longitudinal ligament (PLL) & 20.0 \\
Anterior longitudinal ligament (ALL) & 63.7 \\
Ligamentum flavum (LF) & 40.0 \\
Capsular ligament (CL) & 30.0 \\
Intertransverse ligament (ITL) & 1.8 \\
Interspinous ligament (ISL) & 40.0 \\
Supraspinous ligament (SSL) & 30.0 \\
\hline
\end{tabular}

The vertebra was divided into hard cortical bone on the outside and less dense cancellous bone inside where linear isotropic material properties were imposed for both cortical and cancellous bones [12]. The thickness of cortical was set at $1 \mathrm{~mm}$ [13].

The 3D model of the IVD was created manually using SolidWorks (Dassault Systèmes SolidWorks Corporation) software where the volumetric ratio between the annulus and nucleus was set to $3: 7$ [14]. The top and the bottom surfaces of the disc were constructed such that the surfaces were in contact with the corresponding adjacent surfaces of the vertebral body using Mimics software. The IVD was composed of nucleus pulposus and annulus fibrosis which was modelled as hyperelastic using Mooney-Rivlin formulation $[15,16]$. The annulus was constructed to be composite of a homogenous ground substance reinforced by collagen fibers. The fibers were represented by $3 \mathrm{D}$ truss element with 
TABLE 2: Material properties of the components in the osseoligamentous lumbar spine model.

\begin{tabular}{lccc}
\hline Element set & Element type & Material properties & Reference \\
\hline Cortical bone & 3D tetrahedron & $E=12,000 \mathrm{MPa}, v=0.3$ & {$[16]$} \\
Cancellous bone & 3D tetrahedron & $E=100 \mathrm{MPa}, v=0.2$ & {$[16]$} \\
Articular cartilage & 3D Herman formulation, lower order tetrahedron & {$[15]$} & Mooney-Rivlin: $C_{1}=0.12, C_{2}=0.03$ \\
Nucleus pulposus & 3D Herman formulation, lower order tetrahedron & Mooney-Rivlin: $C_{1}=0.18, C_{2}=0.045$ & {$[12]$} \\
Annulus fibrosis & 3D Herman formulation, lower order tetrahedron & $E=10.0 \mathrm{MPa}(\varepsilon<11 \%), E=20 \mathrm{MPa}(\varepsilon>11 \%)$ & {$[15,18]$} \\
PLL & 3D truss & $E=7.8 \mathrm{MPa}(\varepsilon<12 \%), E=20 \mathrm{MPa}(\varepsilon>12 \%)$ & {$[15,18]$} \\
ALL & 3D truss & $E=15.0 \mathrm{MPa}(\varepsilon<6.2 \%), E=19.5 \mathrm{MPa}(\varepsilon>6.2 \%)$ & {$[15,18]$} \\
LF & 3D truss & $E=7.5 \mathrm{MPa}(\varepsilon<25 \%), E=32.9 \mathrm{MPa}(\varepsilon>25 \%)$ & {$[15,18]$} \\
CL & 3D truss & $E=10.0 \mathrm{MPa}(\varepsilon<18 \%), E=58.7 \mathrm{MPa}(\varepsilon>18 \%)$ & {$[15,18]$} \\
ITL & 3D truss & $E=10.0 \mathrm{MPa}(\varepsilon<14 \%), E=11.6 \mathrm{MPa}(\varepsilon>14 \%)$ & {$[15,18]$} \\
ISL & 3D truss & $E=8.0 \mathrm{MPa}(\varepsilon<20 \%), E=15.0 \mathrm{MPa}(\varepsilon>20 \%)$ & {$[15,18]$} \\
SSL & 3D truss & {$[\varepsilon, 4$}
\end{tabular}

E: Young's modulus; $v$ : Poisson's ratio; $\varepsilon$ : strain; $C_{1}$ and $C_{2}$ : material constant characterising the deviatoric deformation of material.

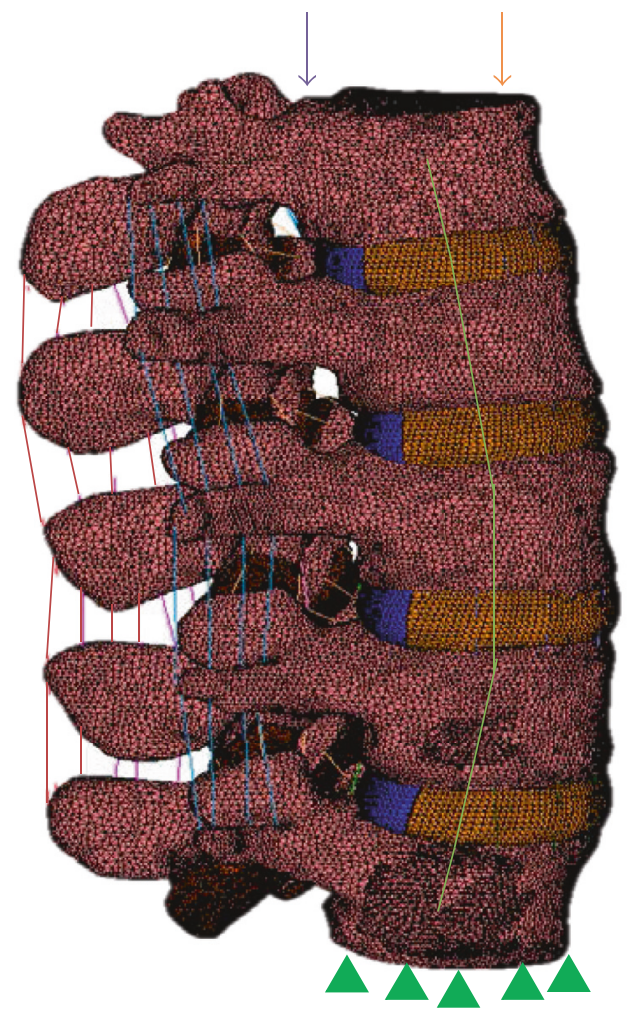

Extension moment point

Follower load path

Flexion moment point

Fixed displacement

FIGURE 2: Loading and boundary condition of FE model of the lumbar spine.

nonlinear stress-strain curve material properties and the angle varied from $\pm 24^{\circ}$ to $\pm 46^{\circ}[12,15]$.

The facet cartilage area was set as hyperelastic using the Mooney-Rivlin formulation with the thickness of $2 \mathrm{~mm}$ $[12,16]$. The articulating facet surfaces were modelled as
TABle 3: Magnitude of moment loading applied on the lumbar spine.

\begin{tabular}{lcccc}
\hline \multirow{2}{*}{ Loading direction } & \multicolumn{2}{c}{ Flexion moment } & \multicolumn{2}{c}{ Extension moment } \\
& $F_{y}(\mathrm{~N})$ & $F_{z}(\mathrm{~N})$ & $F_{y}(\mathrm{~N})$ & $F_{z}(\mathrm{~N})$ \\
\hline Flexion & $-98 \mathrm{~N}$ & $-230 \mathrm{~N}$ & $98 \mathrm{~N}$ & $230 \mathrm{~N}$ \\
Extension & $98 \mathrm{~N}$ & $230 \mathrm{~N}$ & $-98 \mathrm{~N}$ & $-230 \mathrm{~N}$ \\
\hline
\end{tabular}

surface-to-surface contact with $0.5 \mathrm{~mm}$ initial gap where the normal contact stiffness was $200 \mathrm{~N} / \mathrm{mm}$ and the friction coefficient is zero [15]. This will only allow the compressive force to be transmitted within the gap between the articulating facet surfaces $[15,17]$.

The ligaments were represented using truss elements. Table 1 shows the geometrical parameter of the lumbar spine ligaments $[15,18]$. The complete list of the material properties imposed in the FE model of the osseoligamentous lumbar spine is presented in Table 2.

Mesh convergence analysis was performed in order to obtain an optimum FE model of the lumbar spine. Four FE models of L4-L5 lumbar segment were developed using $1.5 \mathrm{~mm}, 2.0 \mathrm{~mm}, 2.5 \mathrm{~mm}$, and $3 \mathrm{~mm}$ mesh sizes. The analysis was based on the IDP results of the IVD where the optimum mesh size started at $2 \mathrm{~mm}$ as the IDP reached a plateau value. The $2.0 \mathrm{~mm}$ was then applied in FE model of L1-L5 lumbar spine [12].

2.2. Finite Element Analysis. The contact surfaces between the vertebral bodies and the IVD were set as perfectly connected to each other using segment to segment contact algorithm in Marc Mentat software. The FE model was subjected to follower load of $500 \mathrm{~N}, 800 \mathrm{~N}$, and $1200 \mathrm{~N}$ which represent the typical human normal weight, overweight, and obesity based on $65 \%$ of upper body weight with an additional $200 \mathrm{~N}$ of local muscle force $[19,20]$. Pure moment of $7.5 \mathrm{Nm}$ was generated using force couple applied at flexion 


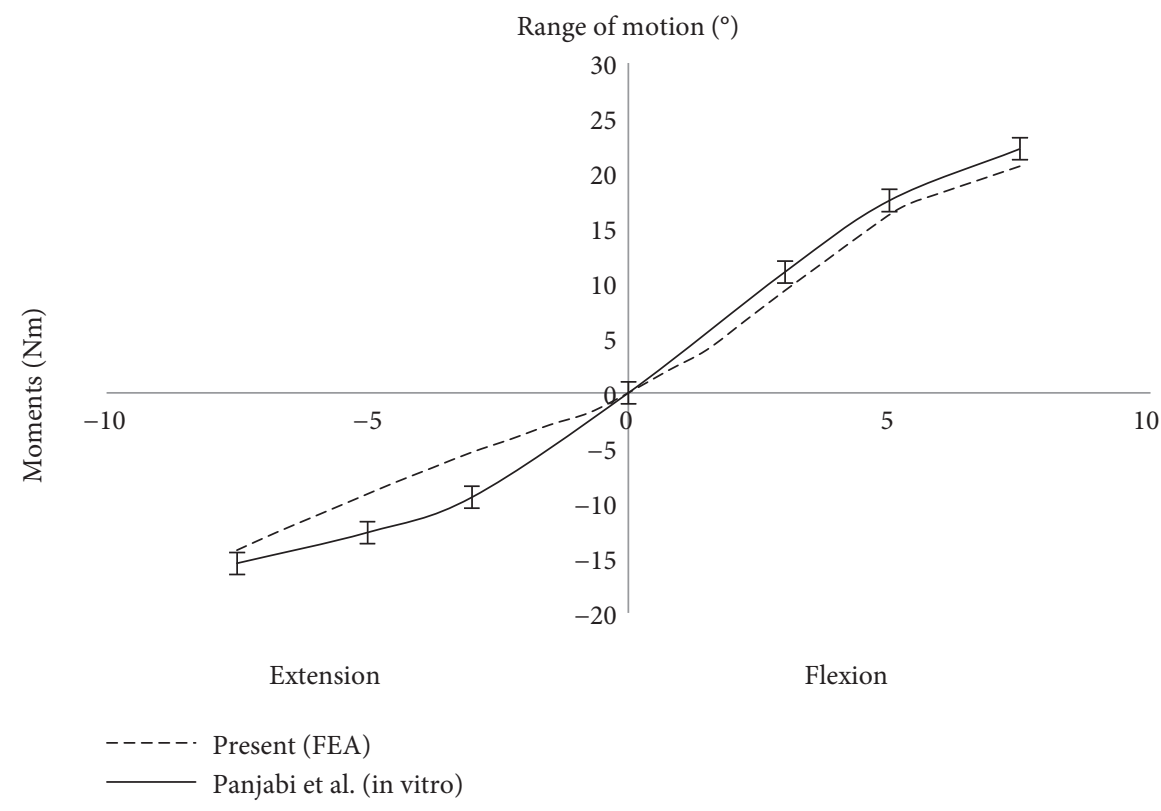

Figure 3: Comparison of ROM between present FE model and previous in vitro result under $7.5 \mathrm{Nm}$ pure moments.

and extension moment points (Figure 2) to create either flexion or extension motions [21, 22]. The force couple consists of two equal and opposite forces as shown in Table 3 [23].

Eight spring elements were applied around the L1-L5 lateral vertebral body where the total load was divided equally to each of the spring element $[24,25]$. This is to assure the uniformity of the applied follower load and to avoid any potential rotation of the intervertebral body. The inferior surface of the L5 vertebral body was completely fixed in all directions as shown in Figure 2.

\section{Results}

3.1. Verification of FE Model. The FE model of osseoligamentous lumbar spine was verified by comparing the range of motion (ROM) with previous in vitro study for flexion and extension motions at pure moment of $7.5 \mathrm{Nm}$. The present results of the intersegmental rotations of the lumbar spine follow similar trend to the previous in vitro results as shown in Figure 3 [21]. The percentage difference of the ROM between present and previous in vitro study in flexion was $7.5 \%$ at $7.5 \mathrm{Nm}$. Although notable difference was found between $2 \mathrm{Nm}$ and $5 \mathrm{Nm}$ in extension motion of the lumbar spine, the percentage difference of the ROM was decreased to $8.1 \%$ when reaching $7.5 \mathrm{Nm}$ moments.

Further comparisons were also carried out to examine the axial displacement and IDP of IVD at L4-L5 vertebral segment. It was found that similar trends were observed in the previous in vitro studies as shown in Figure $4[26,27]$. The differences between the present FEA results and previous in vitro study results for axial displacement and IDP of the IVD at $1200 \mathrm{~N}$ compression load were $7.1 \%$ and $6.9 \%$, respectively. Based on these results, the developed FE model could produce appropriate and reliable results for further FE analysis.
3.2. The Effects of Human Weight on the Intradiscal Pressure. Figure 5 shows the comparison of the IDP of nucleus pulposus for each IVD vertebral segments in the lumbar spine. It was found that the IDP was increased as the human spine physiological loading increased in flexion motion where the highest pressure was $1.26 \mathrm{MPa}$ at L1-L2 vertebral segment. The IDP was increased in flexion motion but an opposite trend was observed in extension motion. The effects of the human weight were observed to be more significant at the L4-L5 segment as shown in Figure 6. In flexion motion, the $1200 \mathrm{~N}$ load generated 30\% higher pressure than the $500 \mathrm{~N}$ load, respectively, whereas in extension motion, the pressure decreased to $80 \%$. At other vertebral levels, the difference of the IDP between $500 \mathrm{~N}$ and $1200 \mathrm{~N}$ loads ranges from $4 \%$ to $8 \%$ in flexion motion, whereas higher range was obtained between $18-60 \%$ in extension motion.

3.3. The Effects of Human Weight on Annulus Fibrosis. In general, the annulus stress increased as the human weight increased with the maximum annulus stress of $3.9 \mathrm{MPa}$ for $1200 \mathrm{~N}$ load at L1-L2 lumbar segment as shown in Figure 7. The highest increment was observed at the L4-L5 where the annulus stress increased to $17 \%$ in extension motion, whereas in flexion motion, the annulus stress increased to $10 \%$. At other vertebral levels, the increment of the annulus stress between $500 \mathrm{~N}$ and $1200 \mathrm{~N}$ loads was between $1.3-8 \%$ in extension and $1-8 \%$ in flexion motion.

\section{Discussion}

The present study demonstrates that physiological loading of body weight plays an important role of stress distribution at IVD in the lumbar spine. It was observed that increasing body weight will increase the pressure at nucleus pulposus and annulus fibrosis at all levels of the IVD. Furthermore, the position and direction of motion appears to affect these 


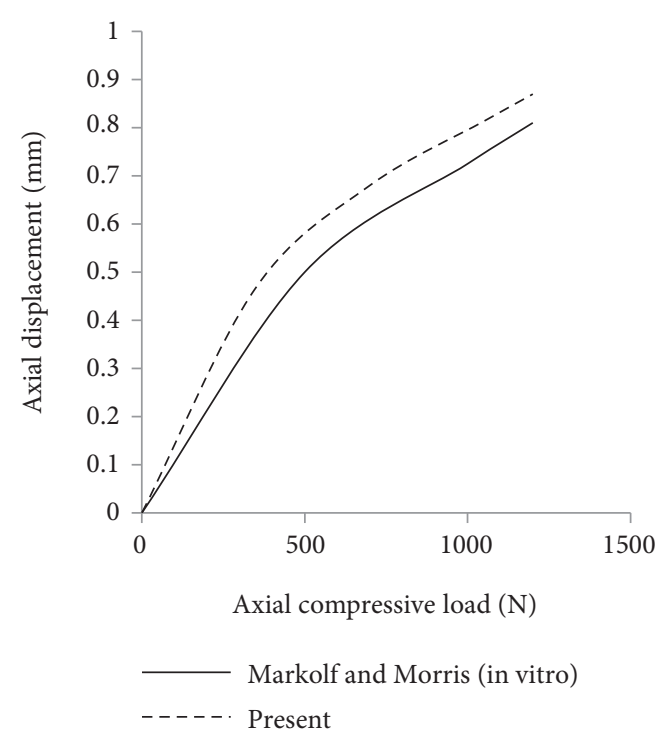

(a)

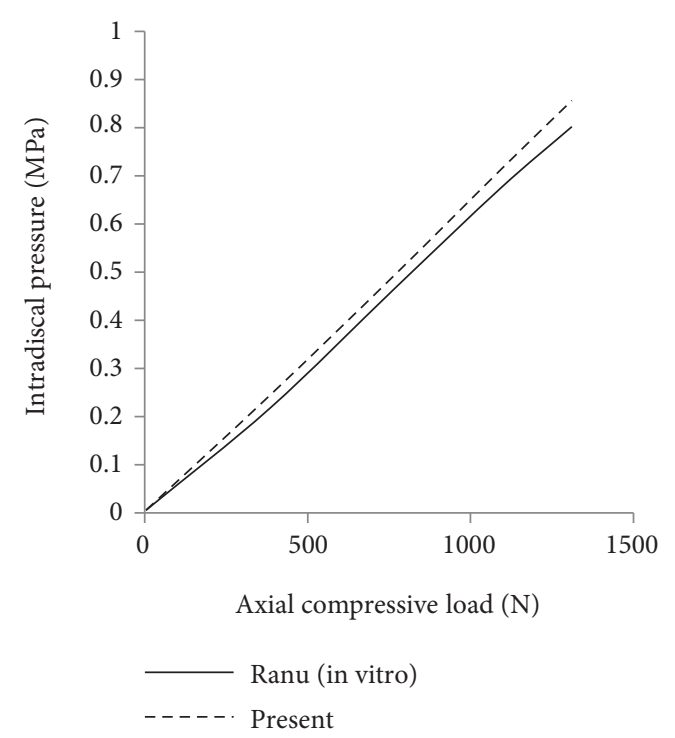

(b)

FIGURE 4: Comparison of present FEA and previous in vitro study of IVD results. (a) Axial displacement and (b) IDP under compressive load up to $1200 \mathrm{~N}$.

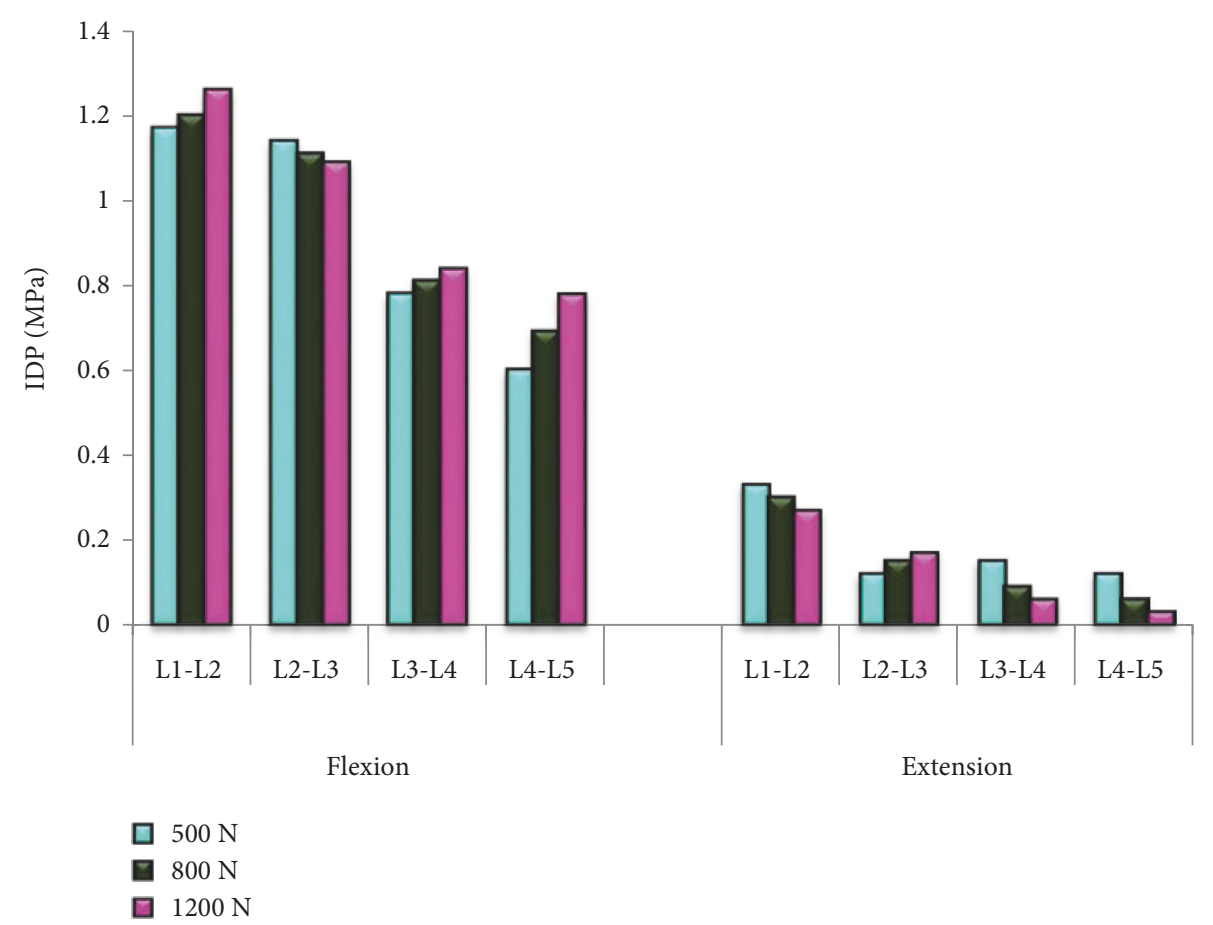

FIGURE 5: Comparison of the IDP of nucleus pulposus for each IVD vertebral segments in the lumbar spine.

results where the IDP was increased in flexion motion but an opposite trend was observed in extension motion. A severe effect was noticed when heavier individuals continue to experience increased stress and pressure on IVD at all vertebral segments in the lumbar spine particularly at L4-L5 segment in both flexion and extension motions.

The results of the present study show similar pattern to the IDP measured in in vitro study where the maximum IDP was found in flexion motion due to the load shift from the posterior towards the anterior of the IVD in flexion motion [12, 28, 29]. The increase of nucleus pressure enhances the tensile stress on the annulus fibers which leads to the excessive stress on the IVD and stimulate the propagation of disc degeneration particularly in nucleus pulposus [21]. This will increase the stiffness of IVD and could reduce its height due to the outflow of fluid through the vertebral body endplates [30]. Subsequently, the fluid loss will increase the proteoglycan and osmotic pressure within the nucleus $[30,31]$. 

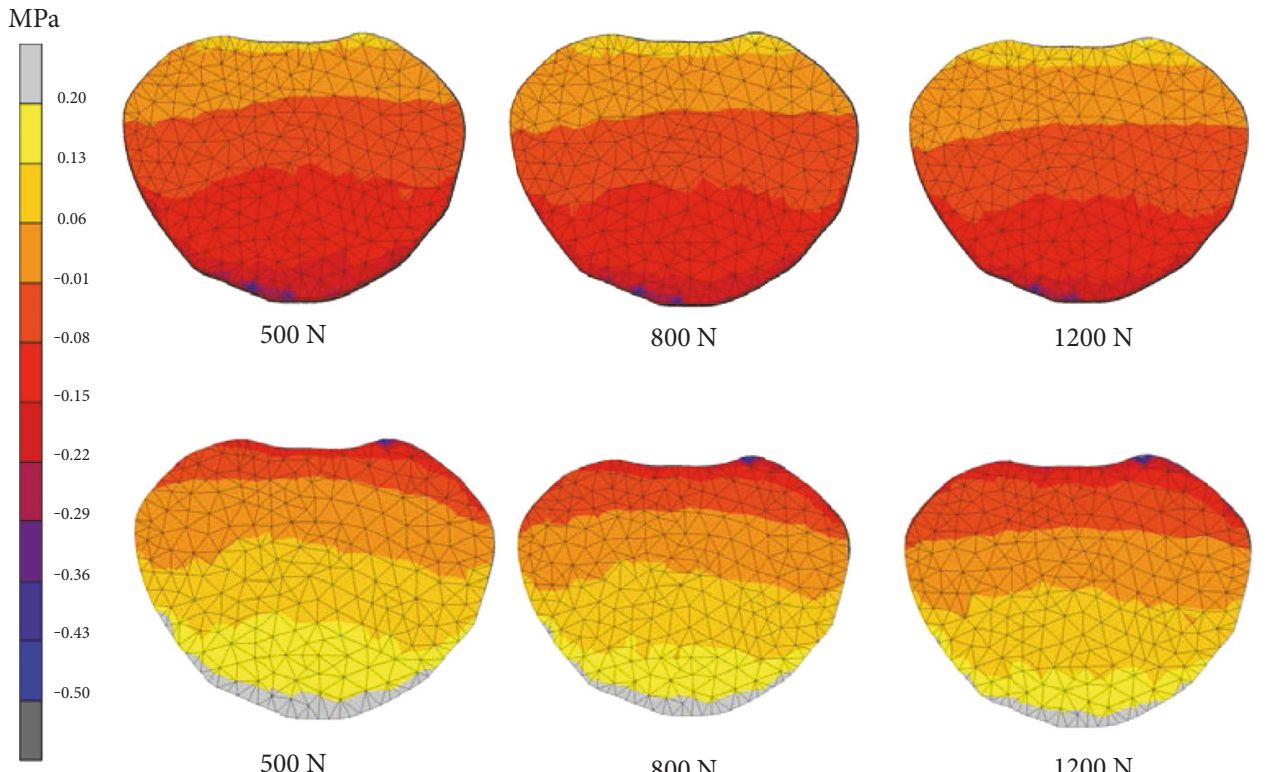

Flexion

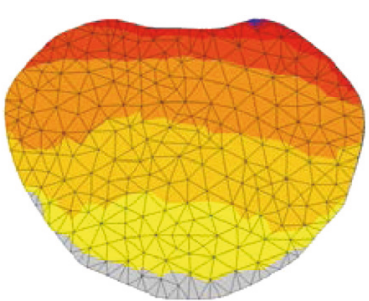

$500 \mathrm{~N}$

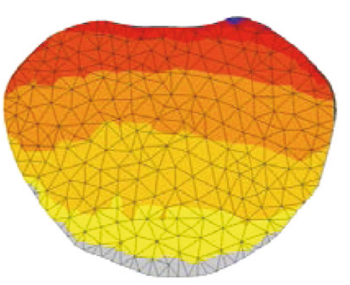

$800 \mathrm{~N}$

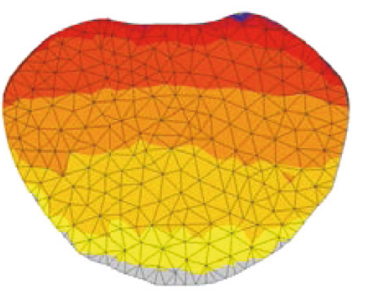

$1200 \mathrm{~N}$

Extension

FIGURE 6: IDP contour plots of nucleus pulposus at L4-L5 vertebral segment.

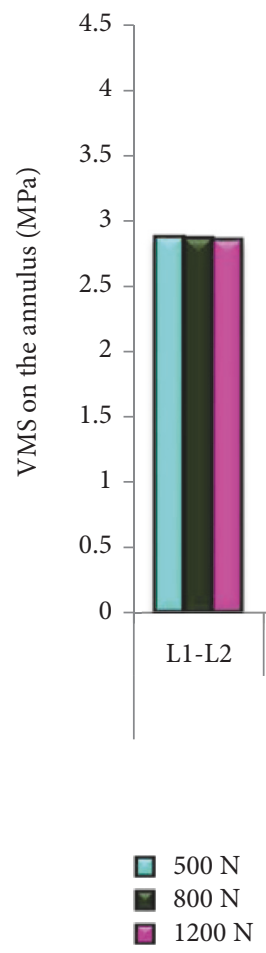

Figure 7: Annulus stress of $500 \mathrm{~N}, 800 \mathrm{~N}$, and $1200 \mathrm{~N}$ loads in flexion and extension motions.

The maximum annulus stress was obtained in extension motion due to the load shift from the anterior towards the posterior of the IVD. This phenomenon was also observed in previous clinical study where the structural defect in the vertebral body endplate tends to distribute the load transferred from the nucleus to the posterior annulus. It has been shown that this can potentially lead to pain and could tear the annulus at the disc rim $[32,33]$.

\section{Conclusion}

Gaining body weight will increase stresses of IVD at all vertebral segments in the lumbar spine particularly the L4-L5 segment. Furthermore, the nucleus pulposus was more severely affected compared with the annulus fibrosus. Although flexion and extension motions of the lumbar spine appear to have different percentage effect on the IVD, it was 
found that heavier individuals will continue to experience an increase in stress at IVD regardless of the position of the spine. This could be a factor that can lead to early intervertebral disc damage.

\section{Conflicts of Interest}

The authors declare that they have no conflicts of interest.

\section{Acknowledgments}

The authors would like to thank the Rehabilitation Engineering and Assistive Technology Research Group, Universiti Teknikal Malaysia Melaka (UTeM) and the Medical Devices and Technology Group, Faculty of Biosciences and Medical Engineering, Universiti Teknologi Malaysia for the valuable research facilities. This research is funded by the Ministry of Higher Education, Malaysia: ERGS/2012/FKM/TK01/02/ 3/E00005.

\section{References}

[1] P. Gordon-Larsen, H. Wang, and B. M. Popkin, "Overweight dynamics in Chinese children and adults," Obesity Reviews, vol. 15, pp. 37-48, 2014.

[2] M. Djurasovic, K. R. Bratcher, S. D. Glassman, J. R. Dimar, and L. Y. Carreon, "The effect of obesity on clinical outcomes after lumbar fusion,” Spine, vol. 33, no. 16, pp. 1789-1792, 2008.

[3] L. Vismara, F. Menegoni, F. Zaina, M. Galli, S. Negrini, and P. Capodaglio, "Effect of obesity and low back pain on spinal mobility: a cross sectional study in women," Journal of NeuroEngineering and Rehabilitation, vol. 7, no. 3, pp. 1-8, 2010.

[4] H. C. D. Porto and C. M. Pechak, "Biomechanical effects of obesity on balance," International Journal of Exercise Science, vol. 5, no. 4, pp. 301-320, 2012.

[5] G. Mellin, K. Harkapaa, H. Vanharanta, M. Hupli, R. Heinonen, and A. Jarvikoski, "Outcome of a multimodal treatment including intensive physical training of patients with chronic low back pain," Spine, vol. 18, no. 7, pp. 825-829, 1993.

[6] K. Martin, K. Fontaine, B. J. Nicklas, K. E. Dennis, A. P. Goldberg, and M. C. Hochberg, "Weight loss and exercise walking reduce pain and improve physical functioning in overweight post-menopausal women with knee osteoarthritis," Journal of Clinical Rheumatology, vol. 7, no. 4, pp. 219223, 2001.

[7] M. A. Adams, "Biomechanics of back pain," Acupuncture in Medicine, vol. 22, no. 4, pp. 178-188, 2004.

[8] A. Rohlmann, S. Neller, L. Claes, G. Bergmann, and H. J. Wilke, "Influence of a follower load on intradiscal pressure and intersegmental rotation of the lumbar spine," Spine, vol. 26, no. 24, pp. E557-E561, 2001.

[9] C. F. Du, N. Yang, J. C. Guo, Y. P. Huang, and C. Zhang, "Biomechanical response of lumbar facet joints under follower preload: a finite element study," BMC Musculoskeletal Disorders, vol. 17, no. 1, p. 126, 2016.

[10] F. Heuer, H. Schmidt, and H. J. Wilke, "Stepwise reduction of functional spinal structures increase disc bulge and surface strains," Journal of Biomechanics, vol. 41, pp. 19531960, 2008.
[11] V. Palepu, M. Kodigudla, and V. K. Goel, "Biomechanics of disc degeneration," Advances in Orthopedics, vol. 2012, Article ID 726210, 17 pages, 2012.

[12] H. Schmidt, A. Kettler, F. Heuer, U. Simon, L. Claes, and H. J. Wilke, "Intradiscal pressure, shear strain, and fiber strain in the intervertebral disc under combined loading," Spine, vol. 32, no. 7, pp. 748-755, 2007.

[13] R. Eberlein, G. A. Holzapfel, and F. Markus, "Multi-segment FEA of the human lumbar spine including the heterogeneity of the annulus fibrosus," Computational Mechanics, vol. 34, no. 2, pp. 147-163, 2004.

[14] V. Moramarco, A. P. D. Palamor, C. Pappalettere, and M. Doblare, "An accurate validation of a computational model of a human lumbosacral segment," Journal of Biomechanics, vol. 43, no. 2, pp. 334-342, 2010.

[15] H. J. Kim, K. T. Kang, B. S. Chang, C. L. Lee, J. W. Kim, and J. S. Yeom, "Biomechanical analysis of fusion segment rigidity upon stress at both the fusion and adjacent segments: a comparison between unilateral and bilateral pedicle screw fixation," Yonsei Medical Journal, vol. 55, no. 5, pp. 13861394, 2014.

[16] W. M. Park, K. Kim, and Y. H. Kim, "Effects of degenerated intervertebral discs on intersegmental rotations, intradiscal pressures, and facet joint forces of the whole lumbar spine," Computers in Biology and Medicine, vol. 43, no. 9, pp. 12341240, 2013.

[17] H. Schmidt, F. Galbusera, A. Rohlmann, T. Zander, and H. J. Wilke, "Effect of multilevel lumbar disc arthroplasty on spine kinematics and facet joint loads in flexion and extension: a finite element analysis," European Spine Journal, vol. 21, Supplement 5, pp. S663-S674, 2012.

[18] C. S. Chen, C. K. Cheng, C. L. Liu, and W. H. Lo, "Stress analysis of the disc adjacent to interbody fusion in lumbar spine," Medical Engineering \& Physics, vol. 23, pp. 483-491, 2001.

[19] A. Rohlmann, N. K. Burra, T. Zander, and G. Bergmann, "Comparison of the effects of bilateral posterior dynamic and rigid fixation devices on the loads in the lumbar spine: a finite element analysis," European Spine Journal, vol. 16, no. 8, pp. 1223-1231, 2007.

[20] M. Kurutz and L. Oroszvary, "Finite element analysis of weightbath hydrotraction treatment of degenerated lumbar spine segments in elastic phase," Journal of Biomechanics, vol. 43, no. 3, pp. 433-441, 2010.

[21] M. M. Panjabi, T. R. Oxland, I. Yamamoto, and J. J. Crisco, "Mechanical behavior of the human lumbar and lumbosacral spine as shown by three-dimensional load-displacement curves lumbosacral behavior spine of the human curves," The Journal of Bone and Joint Surgery American Volume, vol. 76, pp. 413-424, 1994.

[22] S. M. Renner, R. N. Natarajan, A. G. Patwardhan et al., "Novel model to analyze the effect of a large compressive follower pre-load on range of motions in a lumbar spine," Journal of Biomechanics, vol. 40, no. 6, pp. 1326-1332, 2007.

[23] M. Nordin and V. H. Frankel, Basic Biomechanics of the Musculoskeletal System, Lippincott Williams \& Wilkins, Philadelphia, 3rd edition, 2001.

[24] W. Wang, H. Zhang, K. Sadeghipour, and G. Baran, "Effect of posterolateral disc replacement on kinematics and stress distribution in the lumbar spine: a finite element study," Medical Engineering \& Physics, vol. 35, no. 3, pp. 357-364, 2013. 
[25] A. G. Patwardhan, R. M. Havey, G. Carandang et al., "Effect of compressive follower preload on the flexion-extension response of the human lumbar spine," Journal of Orthopaedic Research, vol. 21, no. 3, pp. 540-546, 2003.

[26] K. L. Markolf and J. M. Morris, "The structural components of the intervertebral disc: a study of their contributions to the ability of the disc to withstand compressive forces," The Journal of Bone and Joint Surgery (American Volume), vol. 56, no. 4, pp. 675-687, 1974.

[27] H. S. Ranu, "Measurement of pressures in the nucleus and within the annulus of the human spinal disc: due to extreme loading," Proceedings of the Institution of Mechanical Engineers, Part H: Journal of Engineering in Medicine, vol. 204, no. 3, pp. 141-146, 1990.

[28] O. L. Osti, V. Roberts, R. Moore, and R. D. Fraser, "Annular tears and disc degeneration in the lumbar spine: a postmortem study of 135 discs," Journal of Bone and Joint Surgery, vol. 74, no. 5, pp. 678-682, 1992.

[29] H. Schmidt, A. Kettler, A. Rohlmann, L. Claes, and H. J. Wilke, "The risk of disc prolapses with complex loading in different degrees of disc degeneration: a finite element analysis," Clinical biomechanics, vol. 22, no. 9, pp. 988-998, 2007.

[30] M. A. Adams, D. S. McNally, and P. Dolan, "“Stress" distribution inside intervertebral discs: the effects of age and degeneration," The Journal of Bone and Joint Surgery American Volume, vol. 78, no. 6, pp. 965-972, 1996.

[31] M. A. Adams, S. May, B. J. C. Freeman, H. P. Morrison, and P. Dolan, "Effects of backward bending on lumbar intervertebral discs: relevance to physical therapy treatments for low back pain," Spine, vol. 25, no. 4, pp. 431-437, 2000.

[32] G. Cinotti and F. Postacchini, The Biomechanics. In Lumbar Disc Herniation, Springer Vienna, Vienna, 1999.

[33] B. Johnstone, J. Urban, S. Roberts, and J. Menage, “The fluid content of the human intervertebral disc: comparison between fluid content and swelling pressure profiles of discs removed at surgery and those taken postmortem," Spine, vol. 17, no. 4, pp. 412-416, 1992. 


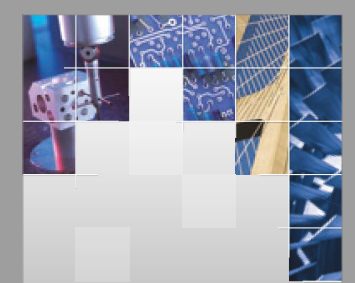

\section{Enfincering}
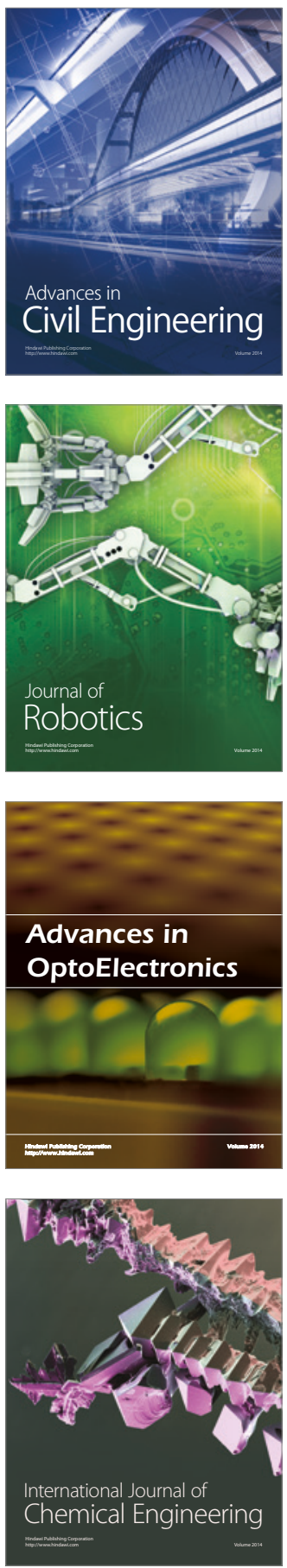

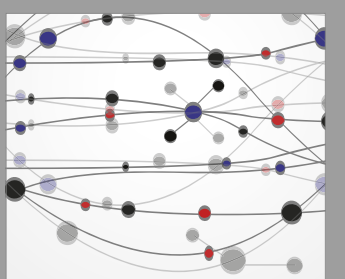

The Scientific World Journal

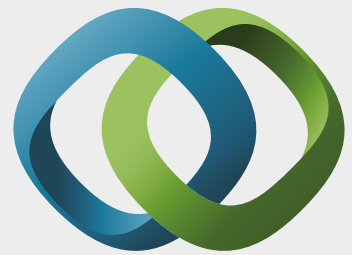

\section{Hindawi}

Submit your manuscripts at

https://www.hindawi.com
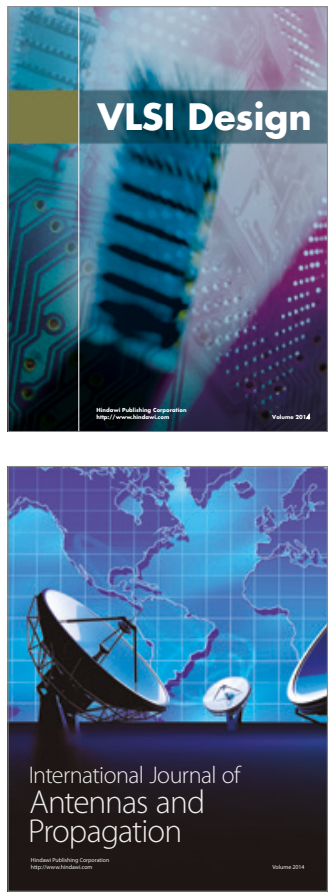

\section{Rotating}

Machinery
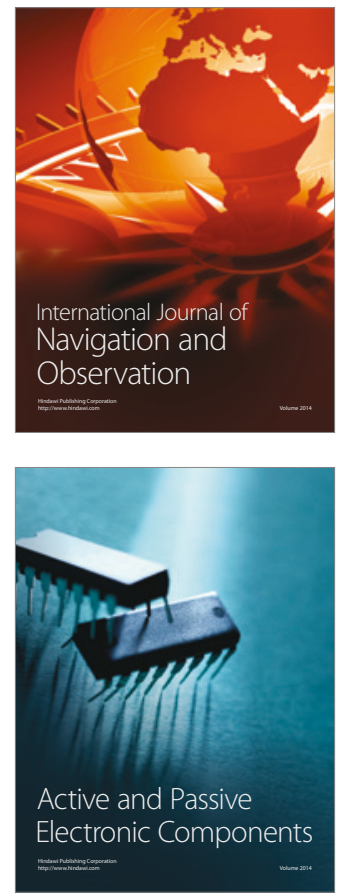
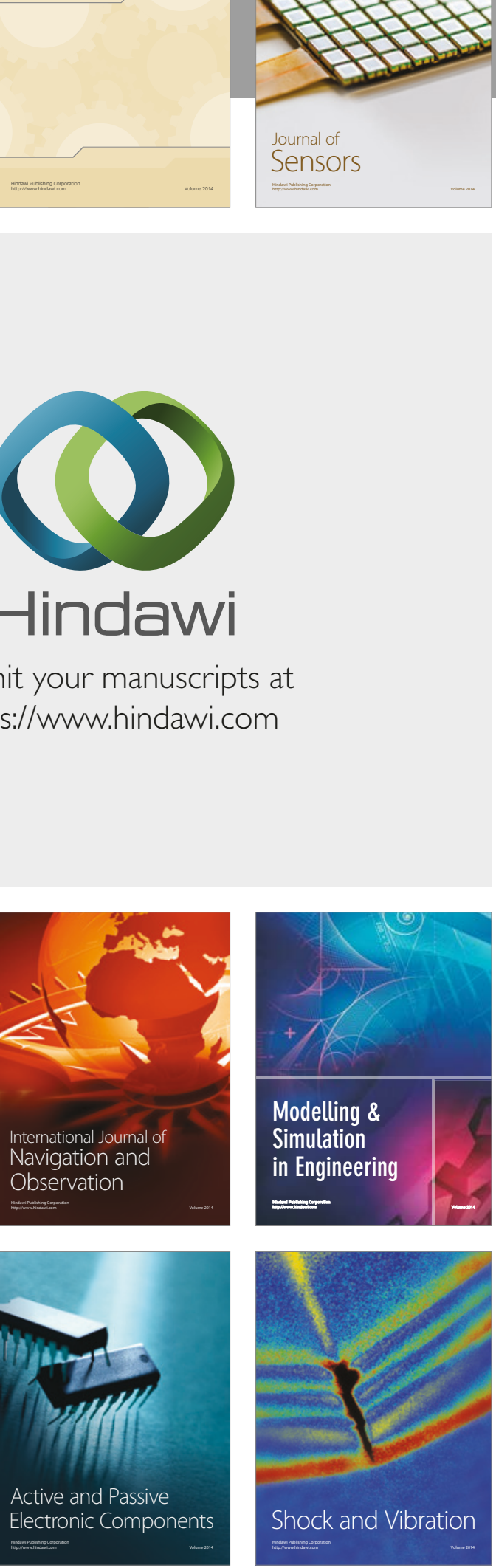
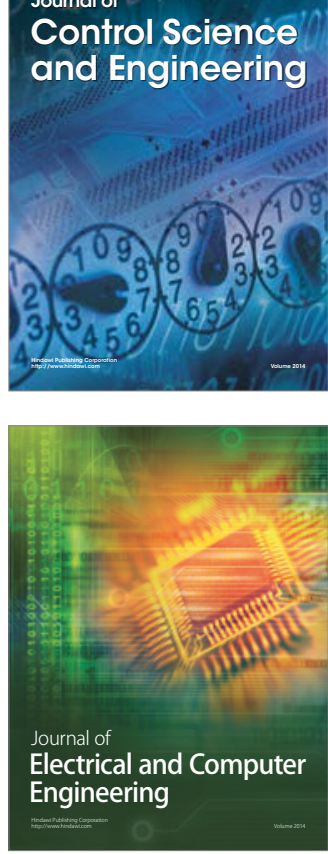

Distributed

Journal of

Control Science

and Engineering
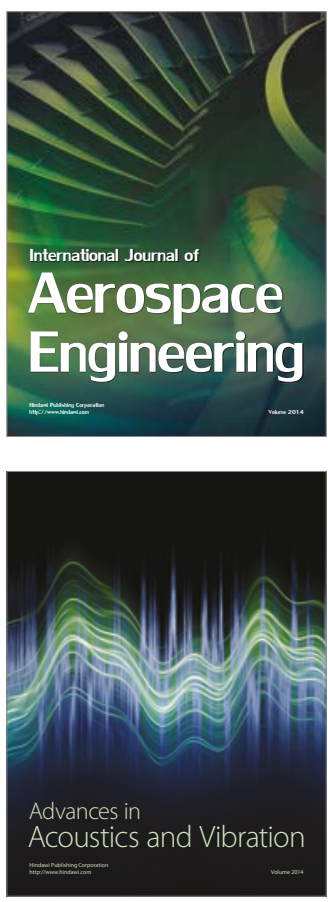

Sensor Networks 